Journal of American Studies, 35 (2001), 3, 4I3-43 I C 200 I Cambridge University Press DOI: 10.1017/S0021875801006697 Printed in the United Kingdom

\title{
Kenneth Burke: Pioneer of Ecocriticism
}

\author{
LAURENCE COUPE
}

Among the sciences, there is one little fellow named Ecology, and in time we shall pay him more attention. He teaches us that the total economy of the planet cannot be guided by an efficient rationale of exploitation alone, but that the exploiting part must eventually suffer if it too greatly disturbs the balance of the whole. ${ }^{1}$

Kenneth Burke, Attitudes Toward History (1937)

\section{BURKE'S REPUTATION}

Nearly every handbook of critical theory acknowledges Kenneth Burke (1897-1993) to be the twentieth-century North American critic who was most ahead of his time. Yet he seems to have been so ambitious that we still do not know how to place him. Indeed, it would require the space of a whole book to trace the extensive but scarcely documented impact which he has had. Concepts for which many other critics became famous may be traced back to him: "the order of words" (Frye); "the rhetoric of fiction" (Booth); "blindness and insight" (De Man); "narrative as a socially symbolic act" (Jameson); "the anxiety of influence" (Bloom). Indeed, it may well be that very anxiety which has led so many contemporary critics to repress his memory. But there is a change in the critical climate, corresponding to the global. This article is written in the hope that Burke will shortly be recognized as the first critic systematically to analyse culture and literature from an ecological perspective. As the dating of our epigraph indicates, he initiated this project over half a century before the rise of ecocriticism in the United States. Moreover, this was no passing phase for him; his whole career may be understood as a profound experiment in green thinking.

Laurence Coupe is Senior Lecturer in English at Manchester Metropolitan University, Manchester Mis 6LL.

${ }^{1}$ Kenneth Burke, Attitudes Toward History (1937; Berkeley: University of California Press, 1984), I 50. 
But, before we pursue Burke's environmental trajectory, perhaps we ought to consider first how his contribution has been understood, where proper attention has been paid prior to the emergence of a green theory. For convenience, I will single out two laudatory accounts by two important critics, both of whom seek to enlist a neglected genius for their causes. The first occurs in a chapter of Geoffrey Hartman's Criticism in the Wilderness (1980), where Burke is celebrated for his resistance to the "model of transcendence." Despite having influenced Northrop Frye, Burke is praised in particular for offering an alternative to his tendency to translate literature into the terms of religious vision, to move smoothly from " words" to "Word." That is, whereas Frye regards all texts under the aspect of the one, inclusive "scared book," subsuming secular diversity under sacred unity, Burke wishes to "demystify spiritual concepts by a 'thinking of the body' that does not devalue them." Instead of imposing order, he engages with "the duplicity of words"; he does not strive for "final synthesis, conversion, or its scientific equivalent: a postulate, like Frye's, separating the study of art from the immediate experience of art." For Burke, writing criticism is itself "a way of establishing an immediate relation to words: the words of others, which remain words about words, the words in oneself, which also remain words about words." Indeed, Hartman wishes to go beyond the illustrative contrast with Frye to claim that Burke's whole enterprise constitutes "a critique of pure thinking as well as of pure poetry." Order must be open to irony. For the urge towards purification is a "visionary disease," the cure for which is demonstrated by Burke's careful attention to "the peculiarly human tools called symbols, of which the 'verbal principle' is recognized even in religion by the term 'Logos.",'2

Hartman's is a useful, succinct summation. However, in order to enlist Burke for his own secular hermeneutics, he perhaps lays too much stress on his hostility to the transcendental impulse: as we shall see, Burke's dialectic involves a constant play of immanence and transcendence. Moreover, despite arguing against pure poetry, he in effect commends Burke as a purely literary critic, thus missing the full extent of his radicalism. By contrast, Frank Lentricchia attempts in his Criticism and Social Change (1983) to effect a wholesale political recuperation of his achievement. If this has the disadvantage of converting Burke's highly independent way of thinking too readily into Marxist terms, it has the

${ }^{2}$ Geoffrey Hartman, Criticism in the Wilderness: The Study of Literature Today (New Haven: Yale University Press, 1980), 91, 92, 94. 
advantage of situating his contribution to North American theory in a wider context. For example, while acknowledging that a disposition towards irony, together with a stress on linguistic performance, might suggest an anticipation of the New Criticism, and while detecting evidence of "formalism," he demonstrates that a consistently social concern redeems the early Burke's apparent aestheticism. This allows Lentricchia to argue that Burke's overall importance is as a model of political insight: "The real force of his thinking is to lay bare, more candidly than any writer I know who works in theory, the socially and politically enmeshed character of the intellectual. To put it that way is to say that Burke more even than Gramsci carries through the project on intellectuals implied by parts of the German Ideology." 3

This explicit association with Marx will perhaps turn out to have been misplaced, once we look at Burke's thinking in more detail. But the emphasis on his sense of historical situation, and of literature as a strategy for engaging with that situation, is well made. For Lentricchia goes on to propose, persuasively, that this kind of responsible criticism, unorthodox in its day, has found itself almost entirely marginalized with the triumph of deconstruction in the United Sates. To illustrate his point, he contrasts Burke with one highly representative theorist, Paul de Man. This is particularly interesting because, as indicated above, the former bequeathed the concept around which he built a critical career. As Lentricchia implies, when Burke speaks of "blindness and insight," he does so in a context which is more than literary, whereas for de Man it provides a way of sealing off the text from the vulgarity of non-literary existence. What the two theorists have in common is irony; what separates them is the function it serves. For Burke it is a strategy of engagement; for de Man it is a rationalisation of evasion. Burke's "exemplary effort" as a "humanist intellectual" is the "linkage" of "the theoretical, the philosophical, and, in the broadest sense, the literary" with "the political process." In de Man Lentricchia sees "something like an attempt at the ultimate subversion of what Burke stands for." The "insidious" effect of his work, with its tone of "resignation and ivory tower despair," is "the paralysis of praxis itself." That is, de Man represents the dead-end of the formalism sponsored by the New Critics. Burke, on the other hand, knows from the outset the limits of the aesthetic dimension even as he seems to espouse it; and his work as a whole is a testimony to the

${ }^{3}$ Frank Lentricchia, Criticism and Social Change (Chicago and London: Chicago University Press, 1983), 62, 38 . 
importance of historical "intervention." "We may or may not agree with Lentricchia's own political agenda, but his account of how the principles of a manifestly engaged critic came to be neglected, even while his name remained resonant, may clarify for us the complex fate of Burke's legacy.

If de Man had come to represent North American critical orthodoxy by the time Criticism and Social Change was written, then Burke was bound to find himself excluded from meta-critical debate. But, since then, we have witnessed a "greening of the humanities" which has made de Man's mandarin textualism seem rather irrelevant. The "paralysis of praxis" is one thing; putting the planet in parenthesis is another. Yet that is what de Man may well be remembered for, now that an ecologically orientated theory has challenged his assumption that the one poetic theme is the power of the human imagination to refuse the claims of nature. ${ }^{5}$ If this is the case, then Lentricchia is right that de Man and Burke are diametrically opposed. As we shall see, Burke it is who denies the possibility of ever making such a refusal, and whose career represents the first major environmental turn in North American theory. For, from his early to his very last writings, his view of literature as a mode of participation in both culture and nature informs his critique of "technological psychosis." We still have much to learn from him.

How much has yet to be agreed. For it is a source of some wonderment that, if the conventional treatment of Burke has been to acknowledge him but rewrite him, American ecocriticism has scarcely begun to recognize him. Here we might refer briefly to Lawrence Buell's monumental work, The Environmental Imagination, whose 560 pages of text contain not one reference to Burke. Perhaps we can understand why if we consider the general drift of the book's argument. Buell is concerned mainly with the question of mimesis, of how nature is represented in "environmental nonfiction" (or "nature writing"). This is not Burke's concern, as green theorist: he foregrounds the question of praxis, of how human beings act in relation to the natural world. Buell regards the main challenge as the legacy of anthropocentrism: while accepting that this legacy must be negotiated rather than negated, he wants to propose a transition from the "egological self" to the "ecological self," by way of an "aesthetics of relinquishment." Burke accepts that a human view of the world will

${ }^{4}$ Ibid., 40.

${ }^{5}$ See Jonathan Bate, Romantic Ecology: Wordsworth and the Environmental Tradition (London: Routledge, I991), 7, 104.

${ }^{6}$ Lawrence Buell, The Environmental Imagination: Thoreau, Nature Writing, and the Formation of American Culture (Cambridge, Mass: Harvard University Press, 1995), I $43 \mathrm{ff}$. 
inevitably be anthropocentric, but argues that human beings have the ability and the responsibility to become as critical as possible of their own motives, insofar as they conflict with the planet's. If Buell is asking that people rethink how they regard nature, Burke's concern is with how they behave towards or within it. Hence he finds drama to be the most useful literary model, since it is about interaction. It is, of course, mimetic in origin, and Burke does not deny the importance of representation; but his own emphasis is pragmatic, being concerned with effect, consequence, impact. The two orientations are not incompatible, and it is worth noting how far his and Buell's interests converge. After all, Buell's own definition of ecocriticism comprehends Burke's enterprise as well as his own: "the study of the relation between literature and environment conducted in a spirit of commitment to environmental praxis. "7 But it is worth insisting that it is Burke more than anyone who has demonstrated what such a relation, such a commitment and such a praxis might involve. This is not surprising, given the extraordinary length of his career, as compared with the recent prominence of academic ecocriticism. Perhaps once that discipline has become fully established, his ambitious, exploratory work will be recognized. Then there might be the opportunity to trace in detail the continuity between Burke and Buell. For a missing name will have been restored to the syllabus.

There is an indirect indication of the need for Burke's influence to be recognized in a pertinent but general observation made by Cheryll Glotfelty, struggling to consolidate ecocriticism in the States in the midI990s:

If your knowledge of the outside world were limited to what you could infer from the major publications of the literary profession, you would quickly discern that race, class, and gender were the hot topics of the later twentieth century, but you would never suspect that the earth's life support systems were under stress. Indeed, you might never know there was an earth at all. In contrast, if you were to scan the newspaper headlines of the same period, you would learn of oil spills, lead and asbestos poisoning, toxic waste contaminations, extinction of species at an unprecedented rate. ${ }^{8}$

Her list goes on tellingly for the duration of a sizeable paragraph; but here her point may assume to have been made. Nor should its relevance to our

7 Ibid., 430.

${ }^{8}$ Cheryll Glotfelty, "Introduction: Literary Studies in an Age of Environmental Crisis," in Cheryll Glotfelty \& Harold Fromm, eds., The Ecocriticism Reader: Landmarks in Literary Ecology (Athens \& London: University of Georgia Press, 1996), xvi. 
discussion be lost. For, though Burke has been cited in many articles written from post-colonial, Marxist and feminist perspectives, it may yet be acknowledged that his most important contribution lay in his foregrounding the earth itself as the ultimate setting of critical activity. In short, he is a pioneer of ecocriticism.

Which brings us, by way of a necessary prologue, to the present task. Given that Burke seems so seldom to be studied, the rest of this article will consist of what might be called corrective exposition: the record has to be set straight. As our epigraph indicates, Burke started using the word "ecology" in 1937, in his Attitudes Toward History. That is one fact that cannot be emphasized enough. However, if we are to be accurate, we should also note that Burke himself points out in his afterword to the third edition of the book (1984) that when he first began using the phrase "ecological balance" he did so "figuratively," applying it to the workings of culture while seeking to bear in mind the wider context of the relationship between culture and nature. ${ }^{9}$ Thus, in proclaiming Burke as a pioneer of ecocriticism, I am not simply saying he was one of the first to suggest that literary theory ought to be aware of ecology; I am also saying that his value to ecocriticism lies in the example he sets of a consistent willingness to cross boundaries and to challenge assumptions in pursuit of a new understanding of humanity's place on the planet. If he has a "lesson" for us, William Rueckert has suggested, it is twofold: "everything implies everything else, and everything is more complicated than it seems."10

\section{"METABIOLOGY"}

To give a fair idea of Burke's development as a pioneer of ecocriticism, we should establish the context in which his very earliest speculations on relationship between art and nature were made. His first critical work, Counter-Statement (193I), might seem at first glance (in the light of Lentricchia's misgivings) to be advocating a pure aestheticism, in line with certain modernist tendencies and in anticipation of the formalism of the New Criticism. Situating the book historically, however, one realizes that it is more appropriately regarded as a riposte to the rise of fascism: that is, it repudiates the attempt to identify nature with "blood and soil," with racial purity, with the triumph of the will. Thus, we should note the

9 Burke, Attitudes Toward History, 4I I.

${ }_{10}$ William H. Rueckert, Kenneth Burke and the Drama of Human Relations (1963; Berkeley: University of California Press, I982), 267. 
pointed phrasing of his "Program" for a projected "Art Party": "Experimentalism, curiosity, risk, dislike of propaganda, dislike of certainty ..."11 However, Burke's case for aesthetic resistance to contemporary totalitarianism may be seen to merge with the wider paradigm of art which he is trying to establish, and upon which he will elaborate throughout his critical career. Thus, though he probably has contemporary right-wing ideology in mind when he further pronounces that "art may be of value purely through preventing a society from becoming too assertively, too hopelessly itself," he is tentatively positing a general principle. ${ }^{12}$ That is, what remains constant in Burke is the refusal of dogmatism; what fascinates the reader is his tireless attempt to decide what that involves: to decide, that is, how exactly "certainty" and "propaganda" are to be countered without surrendering to a chaos of individualistic impulses.

Between espousing a literary programme that might resist totalitarian views of nature and of society, and taking up the term "ecology," Burke wrote the book that may be regarded as his seminal statement: Permanence and Change: An Anatomy of Purpose (1935). It might be said to stand in relation to the rest of his work as does Being and Time to the rest of Heidegger's. ${ }^{13}$ Indeed, the very terms of the title invite comparison: "permanence" is to "Being" as "change" is to "time." Moreover, just as Heidegger might be misunderstood, his terms being taken to form an opposition, so Burke has over the years been accused of essentialism - as if he were simply affirming "permanence" and denying "change." 14 In fact, here as elsewhere, he is concerned with the inextricable relation between the two. The human "purpose" which the book anatomizes is one that proceeds dialectically.

In order to think at all, Burke suggests, we human beings must have an initial "orientation," and this will necessarily involve what the social philosopher Thorstein Veblen calls "trained incapacity" - a "way of seeing" which is simultaneously "a way of not seeing." An orientation will imply a reverence for certain principles, without which it could not function - what Burke calls "piety." If this position is not to lead to dogmatism, it needs to be challenged by a process of "dis-

11 Kenneth Burke, Counter-Statement (1931; Berkeley: University of California Press, I968), III.

${ }^{13}$ For a comparison of the two thinkers, see Samuel B. Southwell, Kenneth Burke and Martin Heidegger (Gainseville: University of Florida Press, 1987).

${ }^{14}$ For a sophisticated version of this charge, as applied to the early work, see Robert Wess, Kenneth Burke: Rhetoric, Subjectivity, Postmodernism (Cambridge: Cambridge University Press, 1987). 
orientation" - what he calls "impiety" or, more specifically, "perspective by incongruity." 15 This opens up possibilities which the initial orientation excludes, forcing us to conceive that there might be other ways of looking at the world. Only then may we achieve "reorientation," a chastened wisdom offering the basis of a new, richer "simplification." This involves a "poetry of action," an "ethical universe-building" informed by a spirit of co-operation. ${ }^{16}$

Thus, abstractly put, the Burkean dialectic might seem to offer only a footnote to the Hegelian. But - and here is the crucial point - the triad of orientation, disorientation and reorientation is designed to explain cultural life without entailing a heavily schematic historicism. For we are to understand that such a process is something in which the human species is continually involved. There is "change" in Burke's model, but there is no telos, no closure, no end that does not imply a new beginning. As for "permanence," he sees his "science of symbolism" as leading back to "a concern with 'the Way,' the old notion of Tao, the conviction that there is one fundamental course of human satisfaction, forever being glimpsed and lost again, and forever being restated in the changing terms of reference that correspond with the changes of historic texture." 17

Here again, the charge of essentialism, or even idealism, might be made; nor would detailed repudiation be easy. By way of reply, and in anticipation of my later argument, I would simply point out here that, for Burke, thinking is always and necessarily attitudinal, and that the invocation of an ancient Chinese principle of fidelity to nature is at least as legitimate methodologically as Marx and Engels' reliance on the hypothesis of "primitive communism." Moreover, the circumspect manner in which Burke invokes the Tao should warn us against a facile debunking of his position. When he makes his case for a "philosophy of being" as opposed to a "philosophy of becoming," he is anxious that it will not be conveniently dismissed as a naïve reaction against historical thinking. As he explains: "In subscribing to a philosophy of being, as here conceived, one may hold that certain historically conditioned institutions interfere with the establishment of decent social or communicative relationships, and thereby affront the permanent biologic norms." 18 Thus, the air may be full of talk of social reform, but this will prove narrow and futile unless there is a sense of the wider relation between human society itself and its non-human context: "for always the

15 Kenneth Burke, Permanence and Change: An Anatomy of Purpose (1935: Berkeley: University of California Press, I984), 69, $74 . \quad{ }^{16}$ Ibid., I67-8.

17 Ibid., I $83-4$. 
Eternal Enigma is there, right on the edge of our metropolitan bickerings, stretching outward to interstellar infinity and inward to the depth of the mind. And in this staggering disproportion between man and no-man, there is no place for purely human boasts of grandeur, or for forgetting that men build their cultures by huddling together, nervously loquacious, at the edge of an abyss." 19

Nor should we assume that Burke's appeal to "permanent biologic norms" and "the Eternal Enigma" is evasive: he really is trying to provide a basis for situating and studying cultural life which might avoid empty progressivism. Though he is not afraid to call this "nature," at this stage he often resorts to feigned inarticulateness, as when, in the introduction to Attitudes Towards History, seeking to persuade his readers that the most important task ahead is to help forestall "the most idiotic tragedy conceivable: the wilful ultimate poisoning of this lovely planet," he appeals to them to "give thanks to Something or Other not of man's making. "20 Seeking to prevent such a tagedy and to promote such a sense of gratitude, Burke propounds a new discipline, "metabiology," which will study the human organism in relation to its environment. ${ }^{21}$ Though Burke has here not yet taken note of the science of ecology, he is no longer distracted by the fascist "blood and soil" from trying to gain an overview on the relation between culture and nature. Indeed, he is proposing here what he will spell out subsequently, that human beings are "bodies that learn language." He is exploring what language adds to bodily life, what culture adds to nature, without opposing the two and without privileging the former and denigrating the latter. Nature, perceived in human terms as non-language, is necessarily the context or referent of the orientation, disorientation and reorientation which are the elements of his "dialectical biologism." In particular, he is trying to get some purchase on that "technological psychosis" which is the reduction to absurdity of "trained incapacity" for it rests on the assumption that there is only one way of perceiving nature, and that is as an object to be exploited.

\section{THE COMIC FRAME}

Attitudes Toward History may not seem a very promising title for the ecocritic. But even though Burke is being largely "figurative" in his application of ecological principles, as he himself admits, the book does

19 Ibid., 272.

20 Burke, "Introduction," Attitudes Toward History (no pagination).

21 Burke, Permanence and Change, 232. 
extend the insights of Permanence and Change into the dialectic of culture and nature, of biological energy and its symbolic expression. Indeed, his overriding aim is to affirm the physical, animal basis of all symbolization. Above all, Attitudes offers a more detailed account of what is involved in human beings" obsession with "becoming" at the expense of "being": that is, it explores what happens when the non-human environment is not only subordinated to the claims of human autonomy but also treated as raw material for human ambition.

The book's premiss is that each literary genre implies a "frame," whether of "acceptance" (epic, tragedy, comedy), or of "rejection" (elegy, satire, burlesque); either way, the frame implies an act of "transcendence," the attainment of a stance beyond contingency. This is, of course, impossible to maintain, which is precisely Burke's point. Similarly, each age has its dominant "attitude," some spiritual "motive" which offers to contain and inform historical experience. This might be conceived as a "collective poem," a work of "folk art"; as such, it is open to "folk criticism," a "collective philosophy of motivation." For the "attitude of attitudes" is a "comic frame" that takes up all the implications and complications of the genre of comedy, as evident in social existence: it offers " the methodic view of human antics as a comedy, albeit a comedy ever on the verge of the most disastrous tragedy." ${ }^{22}$ Here "tragedy" refers to non-generic, material disasters, such as war and pollution; but Burke is also trying to alert us to the symbiotic relationship of the two literary forms. Hence, when he expands on his use of comedy as a model, he refers to its complementary genre:

Like tragedy, comedy warns against the dangers of pride, but its emphasis shifts from crime to stupidity... The progress of humane enlightenment can go no further than in picturing people not as vicious but as mistaken. When you add that people are necessarily mistaken, that all people are exposed to situations in which they must act as fools, that every insight contains its own special kind of blindness, you complete the comic circle, returning again to the lesson of humility that underlies great tragedy. ${ }^{23}$

Having coined the phrase that de Man will appropriate for other ends, he goes on to draw his conclusion and make his commendations:

the comic frame should enable people to be observers of themselves, while acting. Its ultimate would not be passiveness, but maximum consciousness. One would "transcend" himself by noting his own foibles. ... [It] considers human life as a project in "composition," where the poet works with the materials of social

${ }^{22}$ Burke, "Introduction," Attitudes Toward History (no pagination).

${ }^{23}$ Ibid., 4I. 
relationships. Composition, translation, also "revision," hence offering maximum opportunity for the resources of criticism. ${ }^{24}$

According to Burke, human beings have to be particularly careful when they put their principles into practice. Critical alertness is necessary if "the bureaucratization of the imaginative," the attempt to "translate some pure aim or vision into terms of its corresponding material embodiment," is not simply to replace the living spirit with the dead letter (as might be evinced by comparing the message of Jesus with the established church, or Marx's early writings with Stalinist totalitarianism). Only by subjecting cultural activity to what Burke has already proposed in Permanence and Change, namely "perspective by incongruity" (a perspective implicit in the very phrase "bureaucratization of the imaginative"), may an "ecological balance" be effected between the ideal ends and the material means, the spiritual potential and the mundane actualization, the dream and the routine. ${ }^{25}$

The phrase "ecological balance" is certainly pertinent. In his 1984 afterward to Attitudes Toward History, Burke stresses that his project, even in these earlier writings, is to warn against the current mental construction of the non-human world, which amounts in effect to its material destruction. A superficial reading might infer that his position is antitechnological: that he is, in short, the Luddite of caricature. But, as one ponders his position more carefully, one discovers that his object of attack is a particular "attitude," one of naïve faith in the capacity of unbridled "industrialism" to save humanity even as it wastes and pollutes humanity's earthly household. Thus, if the modern era dismissed the "Super-Nature" of previous, more "superstitious" times, then the task of the modern "folk critic" is to challenge the monstrous "CounterNature," the product or expression of the "technological psychosis," which replaced it. ${ }^{26}$ In both cases, a framework of ideas is implied as well as an observable world.

For, just as the "comic frame" of "folk criticism" may draw attention to what human beings are (to adopt an appropriately colloquial idiom) up to, and where they are coming from, it can also remind them what they have missed out on. All "attitudes" imply the remorseless completion of a model: this was true of medieval theology, which sought to situate everything in nature as pointing towards the perfection of God; but nature is far more threatened by the modern "attitude," which attributes absolute status to technology and which reduces everything to the level
${ }^{24}$ Ibid., I71, 173.
25 Ibid., $225-29$.
26 Ibid., 378-79. 
of "instrumentality" in the name of this new, streamlined perfection, whose full realization would necessitate the wholesale destruction of the planet. The dogmas of "hyper-technologism" are to be countered by the "comic corrective," the reminder that human life is a project continually in "composition." For "the comic frame," in making people "observers of themselves," will demonstrate that, whatever "attitude" is adopted, it is likely to offer as much "blindness" as "insight." One strikes an "ecological balance" when one acknowledges what has been excluded, draws the appropriate conclusions and begins to take the appropriate remedial action.

\section{MARXISM, TECHNOLOGY AND "LOGOLOGY"}

Phrases such as "folk criticism" and "bureaucratization of the imaginative" have encouraged some commentators to view Burke chiefly as a left-wing political thinker. We have referred to Frank Lentricchia's valiant effort to recuperate Burke's enterprise for a neo-Marxist theory that might resist the formalism of de Man's deconstruction. Certainly, if Burke's thinking is incipiently green, it is not to be confused with that kind of ecological speculation which denies the claims of society, revering nature to the detriment of culture. However, what needs to be emphasized in any just estimate of Burke's own socially oriented criticism is his willingness to suspect the "piety" of Marxism, and in particular his mistrust of its "technological psychosis."

Let us go back to the sentence quoted earlier from Permanence and Change concerning the need to maintain a "philosophy of being" in order to criticize "certain historically conditioned institutions" which "interfere with the establishment of decent social or communicative relationships, and thereby affront the permanent biologic norms." Now let us note briefly how that particular argument develops: "[One] may further hold that certain groups or classes of persons are mainly responsible for the retention of these socially dangerous institutions." For a "philosophy of being" may commit one to "open conflict with any persons or class of persons who would use their power to uphold institutions serving an antisocial function." 27 If Burke is here providing encouragement for a Marxist critique of capitalism, he is also indicating that Marxism runs the risk of confining itself to the presuppositions of capitalism. Sharply distinguishing his "philosophy of being" from a "philosophy of passivity, or acquiescence," he argues that it has an advantage over Marxist

\footnotetext{
27 Burke, Permanence and Change, 271-72.
} 
historicism, since it allows for a more radical perspective on modernity: 'Our antihistoric position does not in the least imply surrender to historic textures through failure to consider their importance. On the contrary, we believe that in many respects it is the historical point of view which leads to such surrender on the grounds that one must adjust to temporal conditions as he finds them (teaching himself, for example, to accept more and more mechanization simply because the trend of history points in this direction)."28 Cary Wolfe justifies Burke's challenge to Marxism as follows:

What Burke is getting at is that the full critical act must take into account a double dialectical relationship ... The politically engaged critic must now confront not only the dialectic of human history and sociality itself, but also the dialectic between that realm and the environment which gets its nature or meaning from the demands we make of it. ${ }^{29}$

Burke trusts that his "metabiology" offers the grounds for a more complete and more complex dialectic than afforded by Marxism, which seems unable to break with the "piety" of capitalism in order to gain "perspective by incongruity":

The Marxian perspective presents a point of view outside the accepted circle of contingencies. Or, more accurately stated: the Marxian perspective is partially outside this circle. It is outside as regards the basic tenets of capitalistic enterprise. It is inside as regards the belief in the ultimate values of industrialism. ${ }^{30}$

But this "rephrasing of the interactive principle (known in the language of Marxists as dialectical materialism)" in terms of "dialectical biologism" is meant to extend, not deny, its potential for critique: the common emphasis is on "the need of manipulating objective material factors as an essential ingredient to spiritual welfare." The Marxist industrial model falls short in that, like Nietzsche's "will to power," it is "insufficiently methodical." 31 The latter resting content with viewing nature as a jungle, and the former resting content with viewing nature as so much raw stuff to be processed, they both have an impoverished sense of "spiritual welfare."

If "dialectical biologism" is to be preferred to "dialectical materialism," it is because its understanding of the culture-nature relationship is more comprehensive. Much hinges on the definition of the human species. In Attitudes Toward History Burke explicitly states his preference, in traditional Aristotelian terms, for "talking animal" over

28 Ibid., $27 \mathrm{I}$.

${ }^{29}$ Cary Wolfe, "Nature as Critical Concept: Kenneth Burke, the Frankfurt School, and 'Metabiology,"' Cultural Critique, I8 (1991), 77.

30 Burke, Permanence and Change, 224. ${ }_{31}$ Ibid., 229-30, 235. 
"tool-making animal"; but the term he offers of his own is "symbolusing animal." Put starkly, his argument is that if you define human beings by technology, you are unnecessarily exaggerating their rights and underestimating their responsibilities in relation to the planet. If you define human beings by terminology, you are allowing for the permanent possibility of self-critique, since there can be no system, attitude, orientation or frame that does not proceed from the capacity for language. Nearly thirty years after Attitudes Toward History, we can still find Burke working at his linguistic definition. Here he sets it out line by line, phrase by phrase:

the symbol-using (symbol-making, symbol-misusing) animal inventor of the negative (or moralized by the negative) separated from his natural condition by instruments of his own making goaded by the spirit of hierarchy (or moved by the sense of order) and rotten with perfection. ${ }^{32}$

We will return to this striking catalogoue of human attributes; but meanwhile, we obviously cannot let that final, provocative phrase pass without comment. Burke is at once acknowledging that the urge towards completion, fulfilment or "perfection" is in itself a cause for celebration: after all, it has produced, to use the convenient "desert island" conjunction, the Bible and the works of Shakespeare. But his concern is to prevent this urge from spoiling, or even destroying, human and nonhuman life in the course of its "bureaucratization." Specifically, the task of the "folk critic" in our day is to resist arrogant perfectionism by countering it with a method which is alert to those implications and complications ignored by "technological psychosis"-perfectionism gone mad, as it were.

In denying excessive claims for technology, Burke rejects any account of humanity which accepts rampant "industrialism” as its highest achievement. Querying the definition of the human being in terms of labour and advocating a definition in terms of language, Burke early on opposes the Marxist tendency (not evident in the early Marx) towards the unquestioning acceptance of technology, in the name of the discipline he calls "logology." His argument is that if we confine human expectations to the level of production, we will inevitably underplay other possibilities of human culture and overlook the disastrous consequences for nonhuman life. Marxism, for Burke, has become too restrictive a vision of temporal fulfilment. What he proposes instead, since we cannot avoid

${ }^{32}$ Kenneth Burke, "Definition of Man," Language as Symbolic Action: Essays on Life, Literature, and Method (Berkeley: University of California Press, I966), I6. 
following things through to "the end of the line," is a sense of the future that is genuinely open while remaining responsible to human and nonhuman needs:

no political order has yet been envisaged, even on paper, adequate to control the instrumental powers of Technology. Even if you granted, for the sake of the argument, that ("come the Revolution") the utopia of a classless society becomes transformed from an ideality to a reality, there would remain the ever-mounting purely instrumental problems intrinsic to the realm of Counter-Nature as "progressively" developed by the symbol-guided "creativity" of technological prowess itself. $^{33}$

"Logology" - literally, "words about words"-allows Burke that provisional, sceptical transcendence which he elsewhere refers to as "the comic frame." Thus, the Marxist "bureaucratization of the imaginative" stands in need of a meditative overview which can comprehend the "unintended by-products" of technological progress.

\section{THE TRAGIC RITUAL}

In seeking to find and develop a "method" adequate to all the implications and complications of being a "symbol-using animal," Burke constantly returns us to the question of literary genre. As I have already indicated, all Burke's speculations, no matter how wild and wonderful they may seem, are the "matters arising" from his account of comedy and tragedy, of their connections and connotations. We have already considered his case for the "comic frame"; now, finally, we must acknowledge what is involved in the "tragic ritual."

The earlier Burke speaks vaguely of the "collective poem"; the later Burke is much more precise about society as a drama. His theory of "dramatism" complements his "logology": it pursues the practical implications of the definition of humanity offered earlier, in particular the phrases "inventor of the negative" and "goaded by the spirit of hierarchy." Burke argues, no doubt following Hegel, Bergson and others, that human language introduces the capacity for negation into nature. This capacity is not just a matter of saying "no" as well as "yes," or "it is not" as well as "it is." Such denotative usage is far less significant than the hortatory. Moreover, within the language of exhortation, he is especially interested in what follows once "thou shalt not" is understood as the dialectical accompaniment to "thou shalt." "Dramatism" analyses how a society, in being "moved by a sense of order," will be "moralized

\footnotetext{
33 Burke, Attitudes Toward History, 424-25.
} 
by the negative." In other words, in seeking the reassurance of "hierarchy," human beings need some explanation when order is not maintained. The explanation tacitly accepted is the inability to keep the collective commandments ("thou shalt not"). The device for simultaneously alleviating the consequent remorse and purging the error is the discovery of a "scapegoat" to stand in for the group and take away its sense of pollution. Thus, the genre of tragedy, while no doubt being derived from a founding social ritual, is the key to a continuing social ritual:

a dramatistic analysis shows how the negativistic principle of guilt implicit in the nature of order combines with the principles of thoroughness (or "perfection") and substitution that are characteristic of symbol systems in such a way that the sacrificial principle of victimage (the "scapegoat") is intrinsic to human congregation. The intricate line of exposition might be summed up thus: If order, then guilt; if guilt, then need for redemption; but any such "payment" is victimage. Or: If action, then drama; if drama, then conflict; if conflict, then victimage. ... Dramatism, as so conceived, asks not how the sacrificial motives revealed int the institutions of magic and religion might be "eliminated" in a "scientific" culture, but what new forms they might take. ${ }^{34}$

For the later Burke, it is no longer a difficulty to move from the figurative to the literal sense of ecology ; indeed, it is inevitable. Thus, he proceeds, within the scope of the same page, to reflect as follows:

This view of vicarious victimage extends the range of those manifestations far beyond the areas ordinarily so labeled. Besides extreme instances like Hitlerite genocide, or the symbolic "cleansings" sought in wars, uprisings and heated political campaigns, "victimage" would include ... the "bulldozer mentality" that rips into natural conditions without qualms, the many enterprises that keep men busy destroying in the name of progress or profit the ecological balance on which, in the last analysis, our eventual well-being depends, and so on. ${ }^{35}$

Thus, the tragic ritual turns out to be the key to that "technological psychosis" which Burke seeks to diagnose, once a "dramatistic" philosophy of human motives is brought to bear upon it. Firstly, we have to recognize that the ritual of "congregation by segregation" involves "identification" of members of the group by finding their common cause against "the enemy, who serves a unifying function a scapegoat." 36 Secondly, we have to understand where "victimage" ends:

${ }^{34}$ Kenneth Burke, "Dramatism," Communication: Concepts and Perspectives, ed. Lee Thayer (Washington: Spartan Books, 1967), $342 . \quad 35$ Burke, "Dramatism" 342.

${ }^{36}$ Kenneth Burke, "Poetics and Communication," Perspectives in Education, Religion and the Arts, eds. Howard E. Keifer \& Milton K. Munitz (Albany: State University of New York Press, 1970), 413. 
It would be much better for us, in the long run, if we "identified ourselves" rather with the natural things that we are progressively destroying - our trees, our rivers, our land, even our air, all of which we are a lowly ecological part. For here, in the long run, a pious "loyalty to the sources of our being" (Santayana) would pay off best, even in the grossly materialistic sense. For it would better help preserve the kinds of natural balance on which, in the last analysis, mankind's prosperity, and even our mere existence, depend. But too often, in such matters, our attitudes are wholly segregational, as we rip up things that we are not - and thus can congratulate ourselves upon having evolved a way of life able to exhaust in decades a treasure of natural wealth that had been here for thousands of years. ${ }^{37}$

In his final years Burke became preoccupied with this logic, which he increasingly understood was the theme implicit in his earlier work. In a retrospective article written in 1972 he reflects:

in studying the nature of order, I became more and more involved in the conviction that order places strong demands upon a sacrificial principle (involving related motives of victimage and catharsis). Thus, while still opting for comedy, I became fascinated by the symbolism of ritual pollution in tragedy. But during the last couple of years my engrossment has shifted to the evidence of material pragmatic pollution in technology. I loathe the subject, even as I persist in wondering what can possibly be done about it. Men victimize nature, and in so doing they victimize themselves. This, I fear, is the ultimate impasse. ${ }^{38}$

At which point we could bring our account of Burke to a close, acknowledging him to be a prophet of environmental doom. However, he was always a resilent thinker. Significantly, only two years after his acknowledgement of "the ultimate impasse," he made his case for the power of literature to not only reflect but also resist the insane logic of "hyper-technologism." It is worth considering here briefly for the way it deepens and extends the earlier view of the form and function of literature in the face of imminent catastrophe.

"Why Satire, with a Plan for Writing One" is a defence of the literary genre associated with "rejection" rather than "acceptance." Here what is to be rejected is the world we now have, with its implications for the world that we might shortly have. If the human mind always wishes to takes projects through to "the end of the line," and if it proves impervious to "perspective by incongruity," then it will not rest until technology realizes its full potential, even at the expense of the complete pollution and degradation of the planet. Burke's proposed ecological satire would expose the unacknowledged agenda of our "culture of waste": in its bid to create a technological heaven on earth, it will

${ }^{37}$ Ibid., 4I $3^{-1} 4$.

${ }^{38}$ Kenneth Burke, “As I Was Saying," Michigan Quarterly Review, II (1972), 26. 
inevitably produce a hell. The dystopia would hence be called "Helhaven." It would be a variant upon the traditional apocalyptic vision, as may be encountered in the Book of Revelation and in Dante's Divine Comedy, with an appropriate shift of emphasis from sacred to secular. The saved would be the rich: that is, the very people whose material enterprises were responsible for the destruction of the earth would be the only ones able to separate themselves from its effects, by inhabiting a luxurious "culture bubble" on the moon. The damned would be the poor, who would be forced to stay for the duration of the terminal phase of the planet's life. Burke gets no further than sketching the vision of "Helhaven," though he does find space to give ironic praise to Walt Whitman, whose pioneer spirit and meliorism would prove to be the inspiration behind the declarations of "the Master" presiding over the demonic paradise. What is interesting is that he advocates satire as the appropriate genre for our age not only because there is so much that needs rejecting but also because it, too, goes to "the end of the line," imaginatively, exaggerating what is already the case so that we might be alerted to its consequences: its terminological ambition parallels and parodies the technological. ${ }^{39}$

If both comedy and tragedy are "frames of acceptance," then satire, according to Burke"s model of literary creation, arises from radical disaffection. Yet, dedicated as it is to "rejection," it cannot in our time retain its traditional privilege of superior wisdom: ecological catastrophe implicates us all. The very idea that those who had profited from pollution might yet survive its effects, idling their time away in a "haven" or "heaven" built from the rewards of building a "hell" on earth, is close enough to the existing situation (in which the rich have their rural retreats away from the urban noise and squalor they create) to be momentarily credible, but is absurd enough to remind us that the future will most likely be inclusively infernal. Thus, the satire is intended to provoke us into the "collectivist" spirit which Burke's earliest writings had commended. As such, it gestures, paradoxically and painfullly, beyond tragic resignation and towards the potential of the "comic frame."

For, if tragedy is a way of accepting "some natural sorrow, loss, or pain," in Wordsworth's phrase, and ultimately death itself, it should not be allowed to countenance systematic oppression. In the face of such a challenge, the comic sense of incongruity is the preferable mode; it reminds us of the value of what tragic resignation might exclude from the

39 Kenneth Burke, “Why Satire, with a Plan for Writing One," Michigan Quarterly Review, I3 (1974), 307-37. 
picture. Satire, in Burke's sketch for a dystopia, might serve as a reminder of the radical power of the comic attitude, even or especially when it is informed by anger. Certainly, despondent as he became in his later years, he never finally abandoned his central statement of preference, which he had once provided, typically, in the form of a footnote (nearly half of which is in parenthesis), in the course of talking about other things:

Aristotle mentions the definition of man as the "laughing animal," but he does not consider it adequate. Though I would hasten to agree, I obviously have a big investment in it, owing to my conviction that mankind's only hope is a cult of comedy. (The cult of tragedy is too eager to help out with the holocaust. And in the last analysis, it is too pretentious to allow for proper recognition of our animality.) $)^{40}$

In the light of our previous discussion, we may take "comedy" to comprehend "tragedy" and to imply a sense of "ecological balance," to which "the cult of comedy" would be dedicated. We may then see "the cult of tragedy" as a way of conniving in wilful imbalance. But, of course, if we take the full force of the reference to "the holocaust," that way of putting it seems rather too weak. The writer and analyst James Hillman takes the Nazi programme of extermination to be emblematic of all the "devastating enormities" of our era, of the "vast displays of totalitarianism": "burning cities, burning forests, homelessness and hunger. Gargantuan consumerism. Garbage barges, garbage dumps, dead fish, dead skies, and ageless species extinguished en masse." 41 In such a context, we may conclude that it is not only ecocriticics who should take very seriously indeed the "comic corrective" of Kenneth Burke, as a demonstration of how the "victimization" of both people and planet might be resisted.

40 Burke, "Definition of Man," 20.

41 James Hillman, "And Huge is Ugly," Resurgence, I34 (May-June 1989), 4. 